Association and the Mothers and Babies Health Association of South Australia.

37. Requests for reprints should be addressed to: Dr. Leanna C. Read. CSIRO Division of Human Nutrition. Kintore Avenue. Adelaide. South Australia 5000. Australia.
38. This work was supported by grants from the Clive and Vera Ramaciotti Foundations and the Rural Credits Development Fund

39. Received for publication November 9.1982.

40. Accepted for publication April 19,1983

\title{
Measurement of Total Respiratory Resistance in Children by a Modified Forced Oscillation Method
}

\author{
ELIEZER NUSSBAUM ${ }^{(15)}$ AND STANLEY P. GALANT \\ The Pediatric Pulmonary Division. Miller Children's Itospital Medical Center and the Department of Pediatrics. \\ University of California, Irvine, California, USA
}

\section{Summary}

Total respiratory resistance $\left(R_{T}\right)$ was measured in 11 normal children, $2-5.5$ years of age (mean 4.16 years), and in 24 children with bronchial asthma, 2-10.5 years of age (mean 6 years), by oscillating the respiratory system from $2-32 \mathrm{~Hz}$ with a new microprocessor technique. Twenty-five children were $\leq 5$ years of age. This technique was also compared with airway resistance (Raw) by body plethysmography both in terms of baseline values and response to bronchodilators. The absolute values for Raw are lower than $R_{\mathrm{T}}$ with a mean percentage difference ( \pm S.E.M.) of $30.3 \pm 5.0 \%$; however, good correlation between the two techniques was obtained $(r=0.79)$. The changes of $R_{T}$ and $R a w$ were not significantly different after aerosolized isoproterenol $(P$ $>0.05$ ). We determined the inverse relationship between height and $\mathrm{R}_{\mathrm{T}}$ with correlation coefficient $r=-0.79(P<0.01)$. In children, resonant frequency ranged from $6-24 \mathrm{~Hz}$ with a mean value of $16.57 \pm 0.78 \mathrm{~Hz}$. The forced oscillation method utilized clinically in this study provides an alternative to total body plethysmography or an esophageal balloon, which are technically difficult and preclude their routine use in small children.

In conclusion, $R_{1}$ utilized in this study is a rapid and reproducible approximation of Raw. It allows evaluation of $R_{T}$ over a wide range of frequencies including resonant frequency and requires less cooperation than body plethysmography. It requires a relatively short time and allows objective assessment of obstructive airway disease and its responsiveness to bronchodilators in children under 5 years of age.

\section{Abbreviations}

F.O., forced oscillation

$f_{r}$, resonant frequency

Hz, Hertz, which equals cycles per second

Raw, airway resistance

$\mathbf{R}_{\text {T, }}$, total respiratory resistance

Objective assessment of obstructive airway disease requires cooperation and therefore has limited use in children under 6 years of age. In this age group the distinction between normals and those with airway obstruction such as asthmatics or cystic fibrosis patients usually has been based on clinical evaluation. Furthermore, in those children who were diagnosed as having bronchial asthma, the degree of their obstructive airway reversibility after treatment with bronchodilators could not be evaluated nor followed objectively.

Measurements of total respiratory resistance $\left(R_{T}\right)$ by oscillating a sine wave of airflow to the mouth was first described by DuBois et al. $(3,4)$ and later applied to children $(2,9,11-13)$. This F.O. method has been utilized clinically and provides an alternative to total body plethysmography or an esophageal balloon, both of which are technically difficult and therefore preclude routine use in small children. Because $R_{T}$ is the sum of airway resistance and tissue resistance (including chest wall), values should approximate total lung resistance by the esophageal balloon $(2,5$, 6).

The F.O. technique is based on the theory that when a sine wave of airflow is applied to the tracheobronchial tree during spontaneous breathing, the changes in transthoracic pressure are directly related to the total impedance of the system $(2,5,6)$. The total impedance is composed of three elements: effective resistance, inertia, and elastic compliance $(5,6)$. At very low frequencies, less than $2 \mathrm{~Hz}$, elastic impedance dominates but at very high frequencies (above $10 \mathrm{~Hz}$ ) inertial impedance dominates $(2,5-7)$. Between $5-25 \mathrm{~Hz}$, (called the resonant frequency) the inertial and elastic components are of equal magnitude and opposite in sign, and therefore cancel each other. At resonant frequency, pressure and flow are in phase (zero phase angle). Total respiratory resistance can then be calculated from the relationship between pressure and flow, both measured at the mouth of the subject $(4,5,7)$. The mathematical expression of pressure change across the respiratory system include:

$$
\Delta \mathrm{P}=\frac{\mathrm{I}}{\mathrm{C}} \cdot \mathrm{V}+\mathrm{R} \dot{\mathrm{V}}+\mathrm{I} \ddot{\mathrm{V}}
$$

where $\Delta \mathrm{P}$ represents pressure change, $\mathrm{V}$, the resulting volume; $\dot{V}$, the flow rate; $\ddot{V}$, the volume acceleration; $C$, the total respiratory compliance; $\mathrm{R}$, the flow resistance; and $\mathrm{I}$, the mass inertia. At resonant frequency $\Delta \mathrm{P}=\mathrm{R} \dot{\mathrm{V}}$ and therefore $\mathrm{R}=\frac{\Delta \mathrm{P}}{\dot{\mathrm{V}}}$. 
Landser $e t$ al. $(8,10)$ modified the F.O. technique by oscillating the respiratory system at different frequencies simultaneously from $2-32 \mathrm{~Hz}$, thereby allowing the calculation of total respiratory resistance over a spectrum of frequencies. Using this instrument the resonant frequency can easily be derived over a 16-sec interval.

Previously, the use of F.O. in children has not enjoyed wide

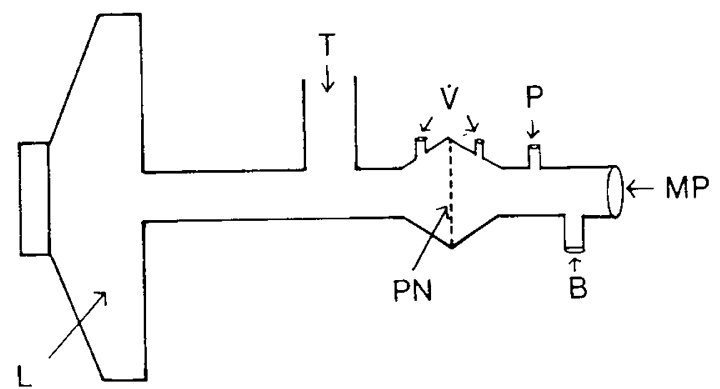

\footnotetext{
$M P=$ Mouthpiece

$P=$ Pressure measured at the mouth

$\dot{V}=\quad$ Measurement of gas flow at the mouth by screen type pneumotachograph

$T=$ Side tube allowing the patient to breathe spontaneously

$L=$ Loudspeaker generating a signal which is superimposed on the patient's spontaneous breathing

$\mathrm{B}=$ Bias-flow produced by a suction pump in order to reduce the dead space in the measuring device

$P N=$ Pneumotachograph
}

Fig. 1. Schematic diagram of measuring device. acceptance because of the difficulty and time consuming nature of performing the test $(2,9,11-13)$. Furthermore, resonant frequency was often not accomplished in the young child with obstructive airway disease and high airway resistance. Measurement of $R_{1}$ in children applying a sine wave at multiple frequencies in a wide spectrum simultaneously has not been described previously.

The purpose of this study was to demonstrate the usefulness of this technique in children under 6 years of age. Specifically, we have compared $R_{T}$ with airway resistance (Raw) by body plethysmography both in terms of baseline values and response to bronchodilators. In addition, we have derived the resonant frequency in normal children and in those with obstructive lung disease, and have established the relationship of $R_{T}$ (at resonant frequency) to height in children.

\section{SUBJECTS AND METHODS}

We studied 48 individuals. The subjects were 11 normal children 2-5.5 years of age (mean, 4.16 years), 24 children with bronchial asthma $2-10.5$ years of age (mean, 6 years), eight normal adults 23-39 years of age (mean, 31 years) and five asthmatic adults $32-43$ years of age (mean, 36.4 years). Asthmatic subjects fulfilled the criteria for bronchial asthma as established by the American Thoracic Society (1).

Multiple frequency f.o. method. The technique was described previously by Làndser et al. (10). Briefly, complex oscillating signal, ranging in frequency from $2-32 \mathrm{~Hz}$, is imposed on the subject's spontaneous breathing. The resulting flow and pressure signals recorded at the mouth by a pneumotachograph and pressure transducers (Validyne, MP 45-1, Engineering Corp., Northridge, CA) are fed into an analog-digital converter (Fa. E. Jaeger, Wurzburg, FRG) and processed by means of a Fourier analysis (PDP 11/04, Digital Equipment Corp., Maynard, MA). The data sampled over a period of $16 \mathrm{sec}$ provides multiple values for analysis. Values with a coherence function smaller than 0.95 are rejected. Figure 1 represents the schematic diagram of the measuring device and Figure 2 shows a 3-year-old boy who is tested in a seated position with noseclip in place while breathing normally with cheeks supported by a technician.

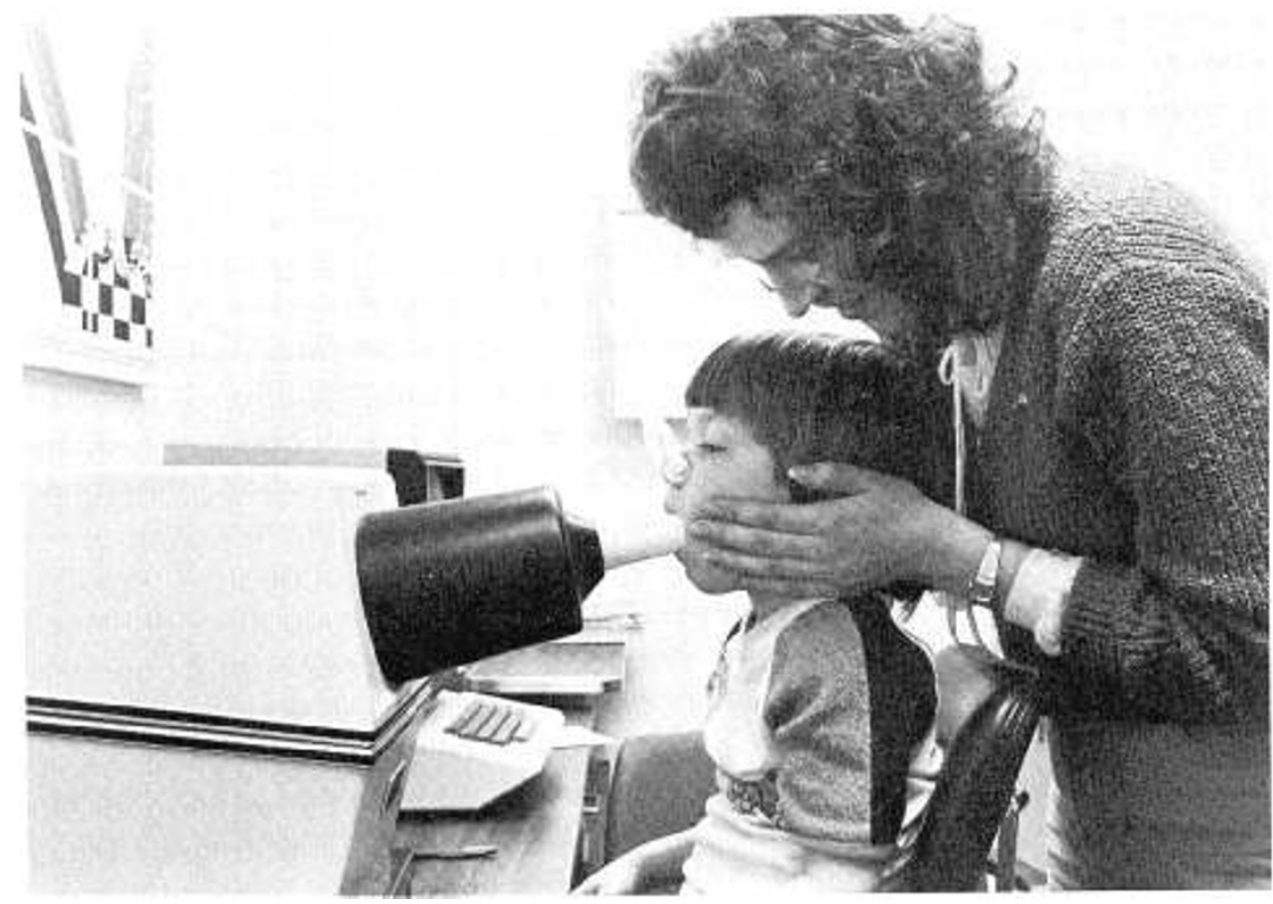

Fig. 2. A 3-year-old boy being tested by the forced oscillation method. (The device is the oscillaire by Jones Medical Instrument Company, Oak Brook, IL, U.S.A.) 
Experimental design. Informed consent was obtained from all parents and subjects were asked to refrain from all medications $12 \mathrm{~h}$ before the test. Measurements were performed in a sitting position with a noseclip in place and children were asked to breathe quietly through a leak-free sealed mouthpiece while supporting their cheeks with both hands. Children under 3 years of age sat on their mothers' lap while their cheeks were supported either by their mother or a technician. A time period of $5 \mathrm{~min}$ was given to those children in order to adapt to this device (the Oscillaire by Jones, Oak Brook, IL). Each measurement lasting $16 \mathrm{sec}$ was repeated at least three times and averaged for each subject. In five children above 6 years of age and in 11 adult patients, Raw was also measured utilizing body plethysmography as described by DuBois et al. (3) Patients were allowed to rest for 15 min and both $R_{\mathrm{T}}$ and Raw were remeasured at $5,10,15$, 20 , and $30 \mathrm{~min}$ after isoproterenol $(0.5 \%)$ aerosol administration $(0.01 \mathrm{cc} / \mathrm{kg}$ with maximum $0.5 \mathrm{cc})$ mixed in $2 \mathrm{cc}$ of normal saline via a No. 561 DeVilbiss air compressor. Aerosolized isoproterenol was administered for 5-10 min through a mouthpiece in children older than 5 years and through a mask in those younger than 5 years.

Data analysis. Nonpaired Student's $t$ test and regression and correlation coefficient analysis were the statistical methods used. The values chosen for analysis represent the highest of three determinations. The intrasubject variability of the forced oscillation technique (standard deviation/mean) estimated from seven subjects was approximately $4 \%$.

\section{RESULTS}

Comparison of $R_{\text {, }}$ and Raw. A comparison of $\mathrm{R}_{\mathrm{T}}$ and $\mathrm{Raw}$ before and after isoproterenol inhalation is seen in Table 1. Data in Table 1 are restricted to comparisons between $R_{T}$ and Raw measurements and consequently the number of asthmatics cliffers from Table 2. The absolute values for Raw are lower than $\mathrm{R}_{\gamma}$ with a mean percentage difference $( \pm$ S.E.M.) of $30.3 \pm 5.0 \%$ for all subject categories before isoproterenol aerosol therapy. Asthmatic children appeared to have considerably greater $R_{\text {. }}$ and Raw values than either adult asthmatics or control adults. For example, asthmatic children had a baseline $\mathrm{R}_{\mathrm{T}}$ of $5.31 \pm$ $0.32\left(\mathrm{cmH}_{2} \mathrm{O} \cdot\right.$ liter $\left.^{-1} \cdot \mathrm{sec}^{-1}\right)$ and $\mathrm{Raw}$ of $4.46 \pm 0.68\left(\mathrm{cmH}_{2} \mathrm{O}\right.$. liter ${ }^{-1} \cdot \mathrm{sec}^{-1}$ ) compared to $\mathrm{R}_{\mathrm{T}}$ values of $2.92 \pm 0.27$ and $2.60 \pm$ 0.14 and Raw values of $2.22 \pm 0.46$ and $1.59 \pm 0.11$ for adult asthmatics and control adults respectively. These differences are statistically significant $(P<0.05)$ for all comparisons between children and adults. After bronchodilator therapy $\mathrm{R}_{\mathrm{T}}$ decreased $17.25 \pm 2.44 \%$ compared with a change in Raw of $15.06 \pm$ $4.15 \%$. The changes in $\mathrm{R}_{\mathrm{r}}$ and $\mathrm{Raw}$ were not significantly different $(P<0.05)$. There appeared to be a significant correlation $r=0.79(P<0.01)$ between $\mathrm{R}_{\mathrm{T}}$ and Raw values as seen in Figure 3.

$R_{T}$ response to bronchodilators and relationship to height. Having verified the $R_{T}$ determination as an approximation of Raw we studied the bronchodilator response in a larger group of asthmatic children with younger mean age group (Table 2). In children the prebronchodilator $\mathrm{R}_{1}$ was $5.93 \pm 0.33\left(\mathrm{~cm} \mathrm{H}_{2} \mathrm{O}\right.$. liter ${ }^{-1} \cdot \mathrm{sec}^{-1}$ ) and after isoproterenol the $\mathrm{R}_{\mathrm{T}}$ was $5.10 \pm 0.28$ $\left(\mathrm{cmH}_{2} \mathrm{O} \cdot\right.$ liter $\left.^{-1} \cdot \mathrm{sec}^{-1}\right)$ for a mean change of approximately $13 \%$. From these data and several control subjects (total of 39 subjects) we determined the relationship between $R_{T}$ and height. As can be seen in Figure 4, there was an excellent inverse relationship between height and $\mathrm{R}_{\mathrm{T}}$ with the correlation coefficient $r=-0.79$, which is highly significant $(P<0.01)$.

Relationship between $R_{T}$ and resonant frequent $\left(f_{r}\right)$. We next explored the relationship between $R_{T}$ and the $f_{r}$ in both adults (Figure 5) and children (Figure 6). Resonating frequency in-

Table 1. Comparison of $R_{T}$ and raw changes after isoproterenol aerosol

\begin{tabular}{|c|c|c|c|c|c|c|c|c|}
\hline Subject & $\begin{array}{l}\text { Age } \\
(\mathrm{yr})\end{array}$ & $\operatorname{Sex}$ & $\mathrm{R}_{\mathrm{T}^{\prime}}$ & $\mathrm{R}_{\mathrm{r}}{ }^{2}$ & $\% \Delta$ & $\mathrm{Raw}_{1}{ }^{\prime}$ & $\mathrm{Raw}_{2}{ }^{2}$ & is \\
\hline \multirow[t]{5}{*}{ Asthmatic children } & 10 & M & 6.00 & 5.56 & 7 & 3.55 & 2.65 & 25 \\
\hline & 9 & M & 3.81 & 3.62 & 5 & 2.43 & 3.22 & -33 \\
\hline & 5.5 & M & 5.81 & 4.19 & 28 & 6.40 & 5.34 & 17 \\
\hline & 10 & M & 5.66 & 4.20 & 26 & 3.40 & 2.75 & 19 \\
\hline & 10.5 & M & 5.29 & 4.62 & 13 & 6.53 & 4.27 & 35 \\
\hline Mean & 9.0 & & 5.31 & 4.44 & 15.8 & 4.46 & 3.65 & 12.6 \\
\hline & \pm & & \pm & \pm & \pm & \pm & \pm & \pm \\
\hline S.E.M. & 0.74 & & 0.32 & 0.26 & 3.89 & 0.68 & 0.42 & 9.6 \\
\hline \multirow[t]{4}{*}{ Asthmatic adults } & 43 & M & 2.56 & 2.12 & 17 & 1.18 & 0.90 & 24 \\
\hline & 33 & $\mathrm{~F}$ & 2.11 & 1.59 & 25 & 1.37 & 1.48 & -7 \\
\hline & 32 & $\mathrm{~F}$ & 3.52 & 3.05 & 13 & 2.60 & 1.84 & 29 \\
\hline & 38 & $\mathrm{~F}$ & 3.48 & 3.49 & 0 & 3.74 & 2.46 & 34 \\
\hline Mean & 36.5 & & 2.92 & 2.56 & 13.8 & 2.22 & 1.67 & 20.0 \\
\hline & \pm & & \pm & \pm & \pm & \pm & \pm & \pm \\
\hline S.E.M. & 1.96 & & 0.27 & 0.33 & 4.0 & 0.46 & 0.25 & 7.2 \\
\hline \multirow[t]{7}{*}{ Control adults } & 35 & M & 3.21 & 2.28 & 29 & 1.40 & 1.17 & 16 \\
\hline & 37 & $F$ & 2.90 & 1.97 & 32 & 2.15 & 1.97 & 8 \\
\hline & 39 & $\mathrm{~F}$ & 1.85 & 1.67 & 10 & 1.53 & 1.44 & 6 \\
\hline & 31 & $\mathrm{~F}$ & 2.63 & 2.06 & 22 & 1.56 & 1.46 & 6 \\
\hline & 27 & $\mathrm{~F}$ & 2.56 & 1.80 & 30 & 1.13 & 0.89 & 21 \\
\hline & 27 & $\mathrm{~F}$ & 2.77 & 2.65 & 4 & 1.86 & 1.21 & 35 \\
\hline & 23 & $F$ & 2.26 & 1.91 & 15 & 1.53 & 1.44 & 6 \\
\hline Mean & 31.3 & & 2.60 & 2.05 & 20.3 & 1.59 & 1.37 & 14.() \\
\hline & \pm & & \pm & \pm & \pm & \pm & \pm & \pm \\
\hline S.E.M. & 1.94 & & 0.14 & 0.11 & 3.56 & 0.11 & 0.11 & 3.6 \\
\hline
\end{tabular}


Table 2. Response in $R$, to isoproterenol aerosol in asthmatic children

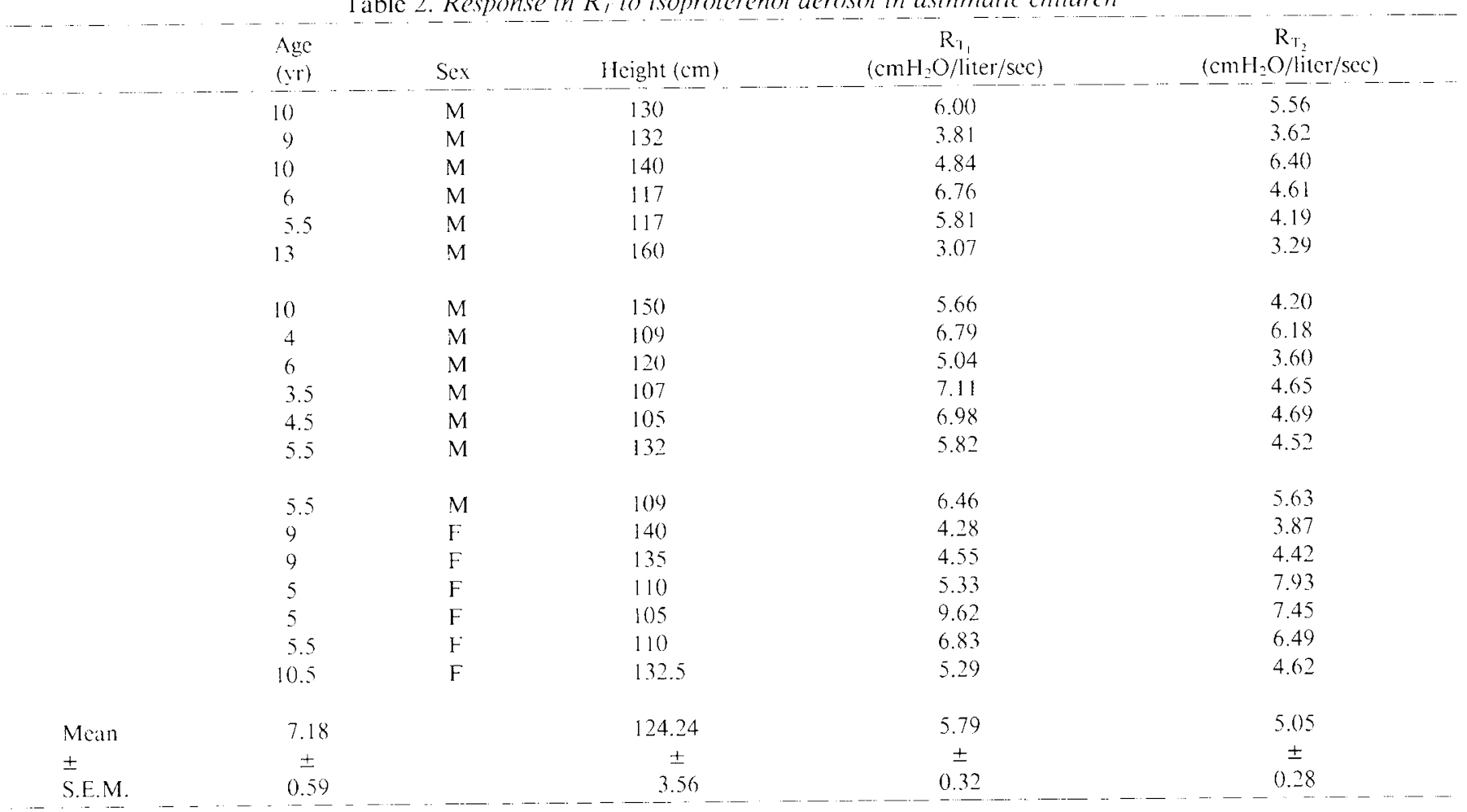

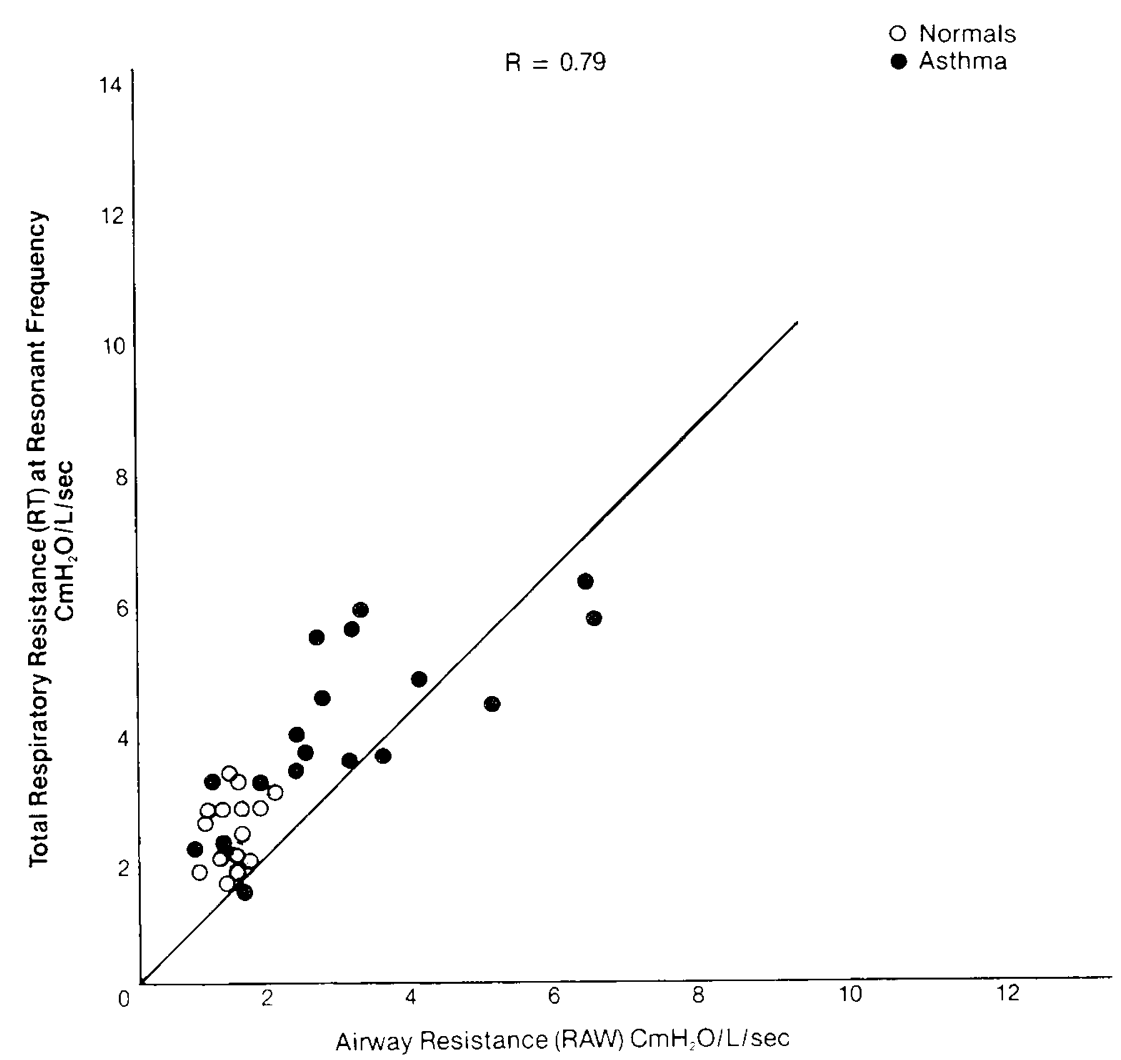

Fig. 3. Correlation between $R_{T}$ and Raw.

creased with increasing $R_{1}$ in normal children and adults as well as those with asthma. Total respiratory resistance correlated well with $\mathrm{f}_{\text {in }}$ adults $(r=0.81, P<0.001)$ whereas the correlation in children was of a lesser degree $(r=0.46, P<0.01)$. In our total population of 35 children (2-10.5 years of age), $f$ range was $6-$ $24 \mathrm{~Hz}$ with a mean value of $16.57 \pm 0.78 \mathrm{~Hz}$ whereas in adults the range was $5-20 \mathrm{~Hz}$ with a mean $\mathrm{f}_{\mathrm{r}}$ of $11.05 \pm 0.65 \mathrm{~Hz}$. This difference in mean $\mathrm{f}_{\mathrm{r}}$ was highly significant $(P<0.001)$. 
RESPIRATORY RESISTANCE

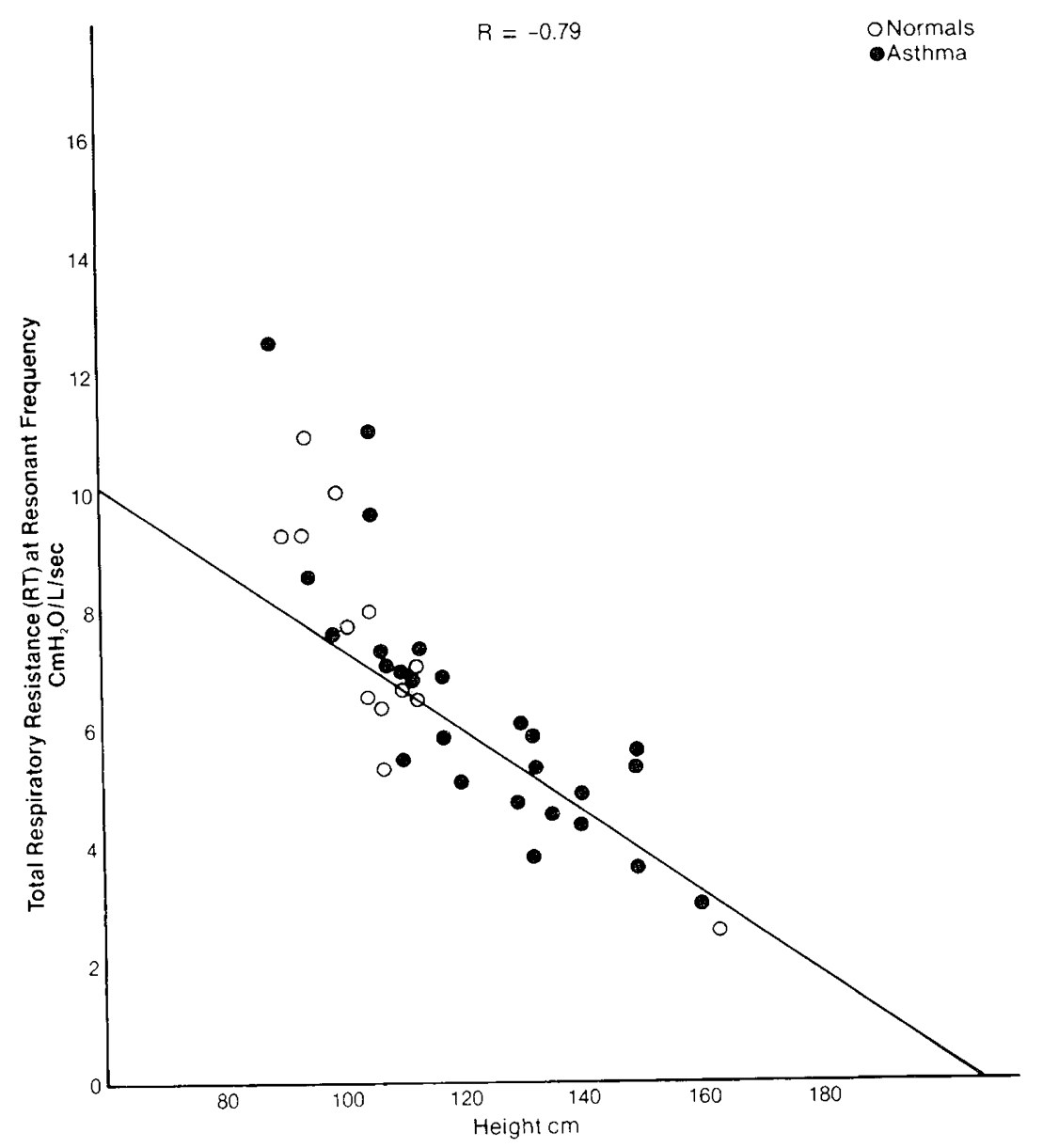

Fig. 4. Inverse relationship of $\mathrm{R}_{\mathrm{T}}$ to height.

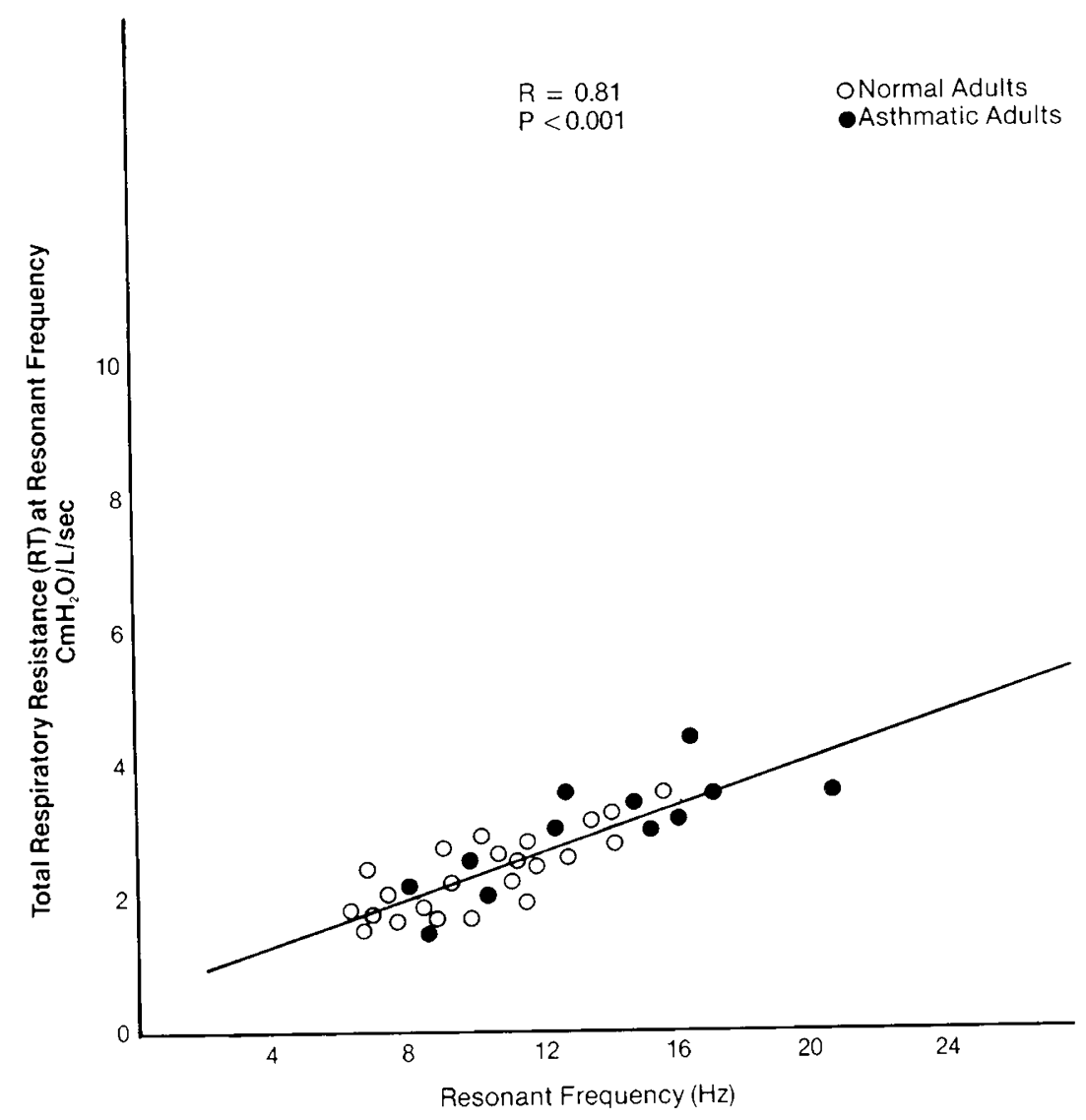

Fig. 5. Relationship of $R_{\mathrm{r}}$ to resonant frequency $\left(\mathrm{f}_{\mathrm{r}}\right)$ in adults. 


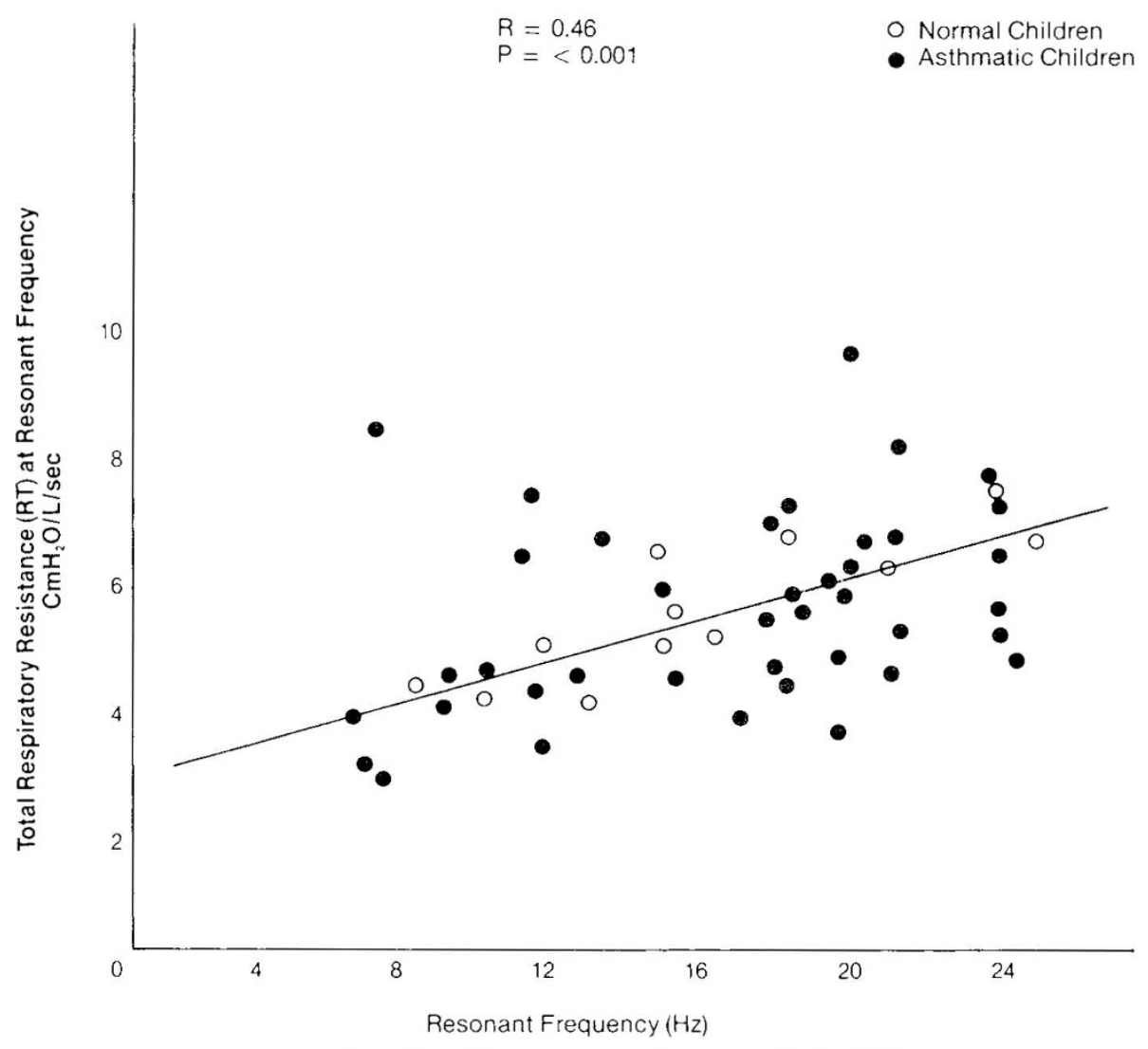

Fig. 6. Relationship of $R_{1}$ to resonant frequency $\left(f_{r}\right)$ in children.

\section{DISCUSSION}

This study represents the first attempt to evaluate $R_{T}$ within a spectrum of frequencies from $2-32 \mathrm{~Hz}$ and to determine $\mathrm{R}_{\mathrm{T}}$ at $f_{r}$ in young children. Our data show that $R_{T}$ at $f_{r}$ is a good approximation of Raw because it reflects similar bronchodilator changes after isoproterenol aerosol $\left(17.25 \pm 2.44 \%\right.$ for $R_{1}$ and $15.06 \pm 4.15 \%$ for Raw). $R_{\text {, generally correlates with the absolute }}$ values of Raw although it is somewhat higher, as would be expected (Fig. 3). In a group of 19 children, with younger mean age group (Table 2), we were able to demonstrate a mean decrease in $\mathrm{R}_{\mathrm{T}}$ of $13 \%$ after isoproterenol. Three patients did not demonstrate a bronchodilator response for reasons that are not clear. If one excludes these three, the mean decrease in those responding was $19 \%$, which would be considered a positive response in comparison to several other pulmonary function techniques. Of the 19 children tested, 11 were 6 years of age or younger and the youngest was 3.5 -years-old. In addition, we demonstrated the correlation between $R_{1}$ and height (inverse) and $f_{i}$. The latter had been suspected, but not shown before.

Although resistance should be calculated during inspiration (7) our measurements provide multiple values for analysis and reject those values with a coherence function smaller than 0.95 . We did not determine lung volume at the resistance measured and it is recognized that lung volumes should be measured in order to achieve diagnostic specificity (5). Although the forced oscillation technique is not a new one. previous studies in children $(2,9,11-13)$ represent only an approximation of $R_{1}$ because their studies were limited to a spectrum of frequencies below resonance. Our measurements of $R_{1}$ within a wide range of frequencies may provide insight into frequency dependence of airway resistance and distribution of ventilation. Cogswell (2). for example concluded from his study that his investigation was limited because it was difficult to find resonance in children with obstructive airway disease. Furthermore, he used $5 \mathrm{~Hz}$ as the only frequency making it impossible to determine $R_{1}$ at $f_{r}$. Other studies were similarly limited because frequencies up to but not exceeding $10 \mathrm{~Hz}$ were used $(2,5,9,11-13)$. Fisher $e t$ al. (5) also recognized that accurate evaluation of $\mathrm{f}_{\mathrm{r}}$ in subjects with obstructive lung disease was frequently not possible. Our study demonstrates quite clearly the relationship between $R_{T}$ and $f_{r}$, confirming previous speculation that $\mathrm{f}_{\mathrm{r}}$ increases with the severity of the airway obstruction (Fig. 5 and 6). Consequently, the scatter of data points in Figure 6 is much greater for asthmatic children than for normal children. It is quite evident that because the mean $f_{r}$ in our population of children was $16.57 \pm 0.78 \mathrm{~Hz}$, the inability to exceed $10 \mathrm{~Hz}$ particularly in children with significant airway obstruction would preclude achieving the measurement of $R_{1}$ at $f_{j}$, which is supposedly a requirement for determining the "true" $R_{1}$.

Similar to previous investigators we were able to show an excellent inverse correlation between the $R_{1}$ and the child's height (12). We disagree, however, that this technique can always be done "quickly and easily." Although this modified instrument designed by Landśer is much faster than previously described instruments capable of measuring $R_{T}$ during a $16-\mathrm{sec}$ period of quiet breathing, much patience is required. The instrument is portable and can be brought to the child's bedside. Attention must also be paid to cheek compression and laryngeal relaxation.

In conclusion, our report suggests that the modified F.O. technique is useful in approximating Raw in the young child who cannot adequately cooperate for other more sophisticated techniques such as body plethysmography. The advantages of this modified technique include achieving $\mathrm{f}_{\mathrm{r}}$ required to measure $R_{1}$ in children and measurements of $R_{1}$ within a wide range of frequencies thus allowing assessment of frequency dependence of respiratory resistance. Other advantages include the short time required to measure $R_{i}(16 \mathrm{sec})$ and the portability of the instrument. We were successful in objectively demonstrating changes in $R_{1}$ in children as young as 3.5 years of age. We recommend the use of F.O. as an objective test in children less than 6-years-old with obstructive airway disease. 
REFERENCES AND NOTES

1. American Thoracic Society Commitiec on Diagnostic Standards for nontuberculous Diseases: Definitions and classification of chronic bronchitis, asthma and pulmonary emphvsema. Am. Rev. Respir. Dis.. 85: 762 (1962).

2 Cogswell. J. J:Forced oscillation technique for determination of resistance to breathing in children. Arch. Dis. Child.. 48: 259 (1973).

3. DuBois. A. B., Botelho. S. Y.. and Comroe. J. H.: A new method for measuring airway resistance in man using a body plethysmograph: Values in normal subjects and in patients with respiratory discase. J. Clin. Invest.. 35: 327 (1956).

4. DuBois. A. B., Brody. A. W.. Lewis. D. H., and Burgess, B. F.. Jr.: Oscillation mechanics of lungs and chest in man. J. Appl. Physiol. 8: 587 (1956).

5. Fisher, A. B.. DuBois, A. B., and Hyde, R. W.: Evaluation of the forced oscillation technique for the determination of resistance to breathing. J. Clin. Invest. 47: 2045(1968).

6. Goldman. M.. Knudson. R. J.. Mead, J. Peterson. N., Schwaber. J. R.. and Wohl. M. E.: $A$ simplified measurement of respiratory resistance by forced oscillation. J. Appl. Physiol.. 28:113(1970).

7. Grimby. G.. Takishima. T., Graham. W.. Macklem. P.. and Mead. J.: Frequency dependence of flow resistance in patients with obstructive lung disease. J. Clin. Invest. 47: 1455 (1968).

8. Holle. J. P.. Landśer. F.. Schüller. B.. Hartmann, V., and Magnussen. H.
Measurement of respiratory mechanics with forced oscillations. Respiration. 41: $119(1981)$.

9. Landau, L. I. and Phelan, P. D.: Evaluation of two techniques for measurement of respiratory resistance by forced oscillation. A study in young subjects with obstructive lung discase. Thorax, 28: 136 (1973).

10. Làndśer. F. J.. Nagels, J.. and van de Woestijne. K. P.: Implementation by means of microprocessor techniques for the measurement of total respiratory impedance during spontaneous brcathing. Prog. Respir. Res.. /I: 135 (1979).

11. Lenney, W and Milner. A. D.: At what age do bronchodilator drugs work? Arch. Dis. Child., 53: 532 (1978).

12. Mansell. A.. Levinson. H., Kruger. K.. and Tripp. T. L.: Measurement of respiratory resistance in children by forced oscillations. Am. Rev. Respir. Dis.. 106: $710(1972)$.

13. Wanner, A. Zarzecki. S. and Marks. M. D.: Continuous measurement of respiratory resistance in asthmatic children. Respiration. 34: 61 (1977).

14. The authors wish to thank Cheryl Nichols for her assistance in the preparation of this manuscript.

15. Requests for reprints should be addressed to: Dr. Eliezer Nussbaum. Director Pediatric Pulmonary Center and Intensive Care Unit. Miller Children's Hospital Medical Center. 2801 Atlantic Avenue. Long Beach. CA 90801.

16. Supported in part by a Grant from the Medical Department of the Boehringer Ingelheim Company.

17. Received for publication June 3,1982.

18. Accepted for publication February 18. 1983

\title{
Intestinal Development in the Suckling Rat: Effects of Weaning, Diet Composition, and Glucocorticoids on Thymidine Kinase Activity and DNA Synthesis
}

\author{
JEAN-PAUL BUTS ${ }^{(42)}$ AND ROGER DE MEYER \\ Division of Experimental Teratology and Medical Genetics. Department of Pediatrics. Lniversity of Lourain. \\ Brussels, Belgium
}

\begin{abstract}
Summary
The present study was designed to determine whether the ontogenic changes in the salvage pathway for DNA synthesis of suckling rat intestine could be causally related to physiologic events during the weaning period. The intestinal activity of soluble thymidine kinase, extremely low in young sucklings (d 11, $0.057 \pm 0.007 \mathrm{nmol} \cdot \mathrm{min}^{-1} \cdot \mathrm{g}$ tissue ${ }^{-1}$ ), increased dramatically between $\mathrm{d} 18$ and 22 postpartum and reached a plateau $(19.8 \pm$ $0.5 \mathrm{nmol} \cdot \mathrm{min}^{-1} \cdot \mathrm{g}$ tissue $\mathrm{e}^{-1}$ ) at the fourth postnatal week. Rat pups prevented from weaning showed an initial rise in the enzyme synthesis by $d 18$ as did their littermates weaned onto an adult diet. Compared with 22 -d-old rats weaned onto chow pellets (14.1 $\pm 2.1 \mathrm{nmol} \cdot \min ^{-1} \mathrm{~g}$ tissue $\left.\mathrm{e}^{-1}\right)$, thymidine kinase concentration was reduced by one-half in rats of the same age, fed on mother's milk alone $\left(6.5 \pm 0.7 \mathrm{nmol} \cdot \mathrm{min}^{-1} \cdot \mathrm{g}\right.$ tissue $\left.\mathrm{e}^{-1}\right)$ or on a liquid artificial diet either high in fat (mimicking rat milk, $7.4 \pm 0.6$ $\mathrm{nmol} \cdot \mathrm{min}^{-1} \cdot \mathrm{g}$ tissue ${ }^{-1}$ ) or high in carbohydrate mimicking chow, $6.4 \pm 1.3 \mathrm{nmol} \cdot \mathrm{min}^{-1} \cdot \mathrm{g}$ tissue $\left.{ }^{-1}\right)$. The relative proportions of fat and carbohydrate in the diet had little or not effect on growth rate, intestinal wt, and DNA content per centimeter. In a second experiment, 9-d-old sucklings were treated for four consecutive d with either saline or hydrocortisone hemisuccinate at doses assumed to be in the physiologic $(0.5 \mathrm{mg} / 100 \mathrm{~g}$ body wt per day)
\end{abstract}

and pharmacologic $(2.0 \mathrm{mg} / 100 \mathrm{~g}$ body wt per day) range. Low doses of the steroid failed to enhance precociously the intestinal synthesis of the enzyme and produced significant decreases in intestinal protein $(-19 \%$ versus controls, $P<0.05)$ and INA content $(-23 \%, P<0.01)$. In the jejunum as well in the ileum, the incorporation rates of $\left[{ }^{3} \mathrm{H} \mid\right.$ thymidine into DNA were reduced to a level about $70 \%$ of the controls $(P=0.05)$. Higher doses of hydrocortisone had a marked suppressive effect on DNA synthesis in the jejunum and ileum, the values in the steroid-treated group being about one-half those of the control group.

During the third week of postnatal life, profound morphologic and biochemical changes occur in rat small intestine. These include increases in intestinal weight, villus and crypt height, cell migration rate, and RNA and DNA content $(16,24)$. The enhanced cell proliferation leads to mucosal hyperplasia, which equally develops in the entire small bowel (3). Intestinal enzymatic activity also undergoes rapid adaptation between $\mathrm{d} 14$ and 21 (14). All these intestinal changes are in the direction of adult values and in many cases, overshoot adult levels. The physiologic mechanisms that initiate and control these maturative events are not well understood. Rats initiate weaning (dietary transition from rat milk to chow) at a critical period, when the intestinal 